Portland State University

PDXScholar

\title{
Efficient Bimolecular Mechanism of Photochemical Hydrogen Production Using Halogenated Boron- Dipyrromethene (Bodipy) Dyes and a Bis(dimethylglyoxime) Cobalt(III) Complex
}

\author{
Randy Pat Sabatini \\ University of Rochester \\ Brian M. Lindley \\ Cornell University \\ Theresa M. McCormick \\ Portland State University, t.m.mccormick@pdx.edu \\ Theodore Lazarides \\ Aristotle University of Thessaloniki \\ William Brennessel. \\ Follow this and additional works at: https://pdxscholar.library.pdx.edu/chem_fac \\ University of Rochester \\ Part of the Physical Chemistry Commons \\ Lee next page for additionalauthors
}

\section{Citation Details}

Sabatini, R. P., Lindley, B. M., McCormick, T. M., Lazarides, T., Brennessel, W., McCamant, D. W., \& Eisenberg, R. (2016). Efficient Bimolecular Mechanism of Photochemical Hydrogen Production Using Halogenated Boron-Dipyrromethene (Bodipy) Dyes and a Bis(dimethylglyoxime) Cobalt(III) Complex. The Journal of Physical Chemistry. B.

This Post-Print is brought to you for free and open access. It has been accepted for inclusion in Chemistry Faculty Publications and Presentations by an authorized administrator of PDXScholar. Please contact us if we can make this document more accessible: pdxscholar@pdx.edu. 


\section{Authors}

Randy Pat Sabatini, Brian M. Lindley, Theresa M. McCormick, Theodore Lazarides, William Brennessel, David W. McCamant, and Richard Eisenberg 
Subscriber access provided by PORTLAND STATE UNIV

\section{Article}

\section{Efficient Bimolecular Mechanism of Photochemical Hydrogen Production Using Halogenated Boron-Dipyrromethene (Bodipy) Dyes and a Bis(dimethylglyoxime) Cobalt(III) Complex}

Randy Pat Sabatini, Brian M. Lindley, Theresa M. McCormick, Theodore Lazarides, William Brennessel, David W. McCamant, and Richard Eisenberg

J. Phys. Chem. B, Just Accepted Manuscript • DOI: 10.1021/acs.jpcb.5b11035 • Publication Date (Web): 05 Jan 2016

Downloaded from http://pubs.acs.org on January 15, 2016

\section{Just Accepted}

"Just Accepted" manuscripts have been peer-reviewed and accepted for publication. They are posted online prior to technical editing, formatting for publication and author proofing. The American Chemical Society provides "Just Accepted" as a free service to the research community to expedite the dissemination of scientific material as soon as possible after acceptance. "Just Accepted" manuscripts appear in full in PDF format accompanied by an HTML abstract. "Just Accepted" manuscripts have been fully peer reviewed, but should not be considered the official version of record. They are accessible to all readers and citable by the Digital Object Identifier (DOI®). "Just Accepted" is an optional service offered to authors. Therefore, the "Just Accepted" Web site may not include all articles that will be published in the journal. After a manuscript is technically edited and formatted, it will be removed from the "Just Accepted" Web site and published as an ASAP article. Note that technical editing may introduce minor changes to the manuscript text and/or graphics which could affect content, and all legal disclaimers and ethical guidelines that apply to the journal pertain. ACS cannot be held responsible for errors or consequences arising from the use of information contained in these "Just Accepted" manuscripts. 


\title{
Efficient Bimolecular Mechanism of Photochemical Hydrogen Production Using Halogenated Boron-Dipyrromethene (Bodipy) Dyes and a Bis(dimethylglyoxime) Cobalt(III) Complex
}

\author{
Randy P. Sabatini, Brian Lindley, Theresa M. McCormick, Theodore Lazarides, William W. Brennessel, \\ David W. McCamant* and Richard Eisenberg* \\ Department of Chemistry, University of Rochester, Rochester, NY 14627
}

\begin{abstract}
A series of Boron-dipyrromethene (Bodipy) dyes were used as photosensitizers for photochemical hydrogen production in conjunction with $\left[\mathrm{Co}^{\prime \prime \prime}(\mathrm{dmgH})_{2} \mathrm{pyCl}\right]$ (where $\mathrm{dmgH}=$ dimethylglyoximate, py = pyridine) as the catalyst and triethanolamine (TEOA) as the sacrificial electron donor. The Bodipy dyes are fully characterized by electrochemistry, x-ray crystallography, quantum chemistry calculations, femtosecond transient absorption and time-resolved fluorescence, as well as in long-term hydrogen production assays. Consistent with other recent reports, only systems containing halogenated chromophores were active for hydrogen production, as the long-lived triplet state is necessary for efficient bimolecular electron transfer. Here, it is shown that the photostability of the system improves with Bodipy dyes containing a mesityl group versus a phenyl group, which is attributed to increased electron donating character of the mesityl substituent. Unlike previous reports, the optimal ratio of chromophore to catalyst is established and shown to be $20: 1$, at which point this bimolecular dye/catalyst system performs 3-4 times better than similar chemically linked systems. We also show that the hydrogen production drops dramatically with excess catalyst concentration. The maximum turnover number of $\sim 700$ (with respect to chromophore) is obtained under the following conditions: $1.0 \times 10^{-4} \mathrm{M}\left[\mathrm{Co}(\mathrm{dmgH})_{2} \mathrm{pyCl}\right], 5.0 \times 10^{-6} \mathrm{M}$ Bodipy dye with iodine and mesityl substituents, 1:1 v:v (10\% aqueous TEOA):MeCN (adjusted to $\mathrm{pH} 7$ ), and irradiation by light with $\lambda>410 \mathrm{~nm}$ for $30 \mathrm{~h}$. This system, containing discrete chromophore and catalyst, is more active than similar linked Bodipy $\mathrm{Co}(\mathrm{dmg})_{2}$ dyads recently published, which, in conjunction with our other measurements, suggests that the nominal dyads actually function bimolecularly.
\end{abstract}




\section{Introduction}

The growth of alternative, carbon-neutral energy sources represents a means to meet the continually rising demand for energy while minimizing environmental change. ${ }^{1}$ The controlled combustion of hydrogen with oxygen is particularly suited for this goal, as the only byproduct of the reaction is water. To generate the necessary hydrogen fuel, water can be split using a photochemical cycle modeled after photosynthesis, whereby the reduction of aqueous protons to $\mathrm{H}_{2}$ and the oxidation of water to $\mathrm{O}_{2}$ comprise the two half reactions. Both reactions include a chromophore, in order to absorb light, and a catalyst, in order to catalyze the reaction. When studying only the reductive production of hydrogen, a source of electrons is also needed and is supplied by a sacrificial electron donor.

For hydrogen production, a deep understanding of the chromophore and catalyst is crucial in building an efficient system. Boron-dipyrromethene (Bodipy) dyes have been well studied as photosensitizers (PS) in the literature, due to high molar absorptivities, tunable absorption and emission energies, and high fluorescence quantum yields. ${ }^{2-4} \mathrm{~A}$ typical Bodipy structure is shown below.

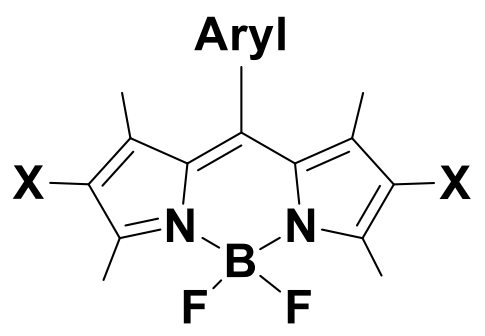

Upon halogenation $(X=B r, I)$, the increased spin-orbit coupling enables intersystem crossing to compete with other modes of decay, generating the long-lived triplet state. This state has been proven useful in systems where bimolecular electron transfer is needed. ${ }^{5}$ The rigidity of the system can also be tuned by choosing bulkier aryl groups, which has been shown to increase the fluorescence quantum yield, presumably by preventing facile torsion, thereby inhibiting the nonradiative rate of internal conversion. ${ }^{6}$

Cobalt dimethylglyoxime $\left(\mathrm{Co}(\mathrm{dmg})_{2}\right)$ complexes represent a class of established catalysts used in a variety of systems for the photoproduction of hydrogen. ${ }^{7-12}$ Recently, several groups have published articles featuring dyads, in which Bodipy chromophores have been covalently bound to $\mathrm{Co}(\mathrm{dmg})_{2}$ catalysts for application in solar energy conversion. ${ }^{13-17}$ In these cases, the Bodipy contains a pyridine aryl group, which coordinates to Co(III) as a ligand on the catalyst. The system was found to be more stable when electron donating substituents made the pyridine 
more basic, ${ }^{13}$ allowing more robust hydrogen production. ${ }^{16}$ While some evidence supports the improvement of $\mathrm{H}_{2}$ production upon complexation of Bodipy with $\mathrm{Co},{ }^{16}$ other results suggest the system may actually be functioning bimolecularly. Luo et al. very recently published an article describing discrete Bodipy chromophores and $\mathrm{Co}(\mathrm{dmg})_{2}$ catalysts (among other systems for solar energy conversion), where only systems containing halogenated Bodipy chromophores were active for $\mathrm{H}_{2}$ production. ${ }^{18}$ The TONs with respect to chromophore reported ${ }^{18}$ were greater than those reported for the earlier dyads. ${ }^{15,16}$ Here, we present the results of a series of discrete Bodipy chromophores and the $\mathrm{Co}(\mathrm{dmg})_{2}$ catalyst, in which the effects of halogenation, sterics, and component concentrations are examined. By optimizing the relative concentrations of the dye and catalyst we show that the system is strongly inhibited under conditions of excess catalyst, as was used in prior studies. The difference between the activity of this system and previously studied dyads is also discussed.

\section{Experimental}

Fluorescence Quantum Yield Measurements. Absorption spectra were measured using a Hitachi U2000 scanning spectrophotometer. Emission spectra were measured using a Spex Fluoromax-P fluorometer. Based on spectral overlap considerations, fluorescein in $0.1 \mathrm{M} \mathrm{NaOH}(\mathrm{aq})$ was used as the quantum yield standard for compounds $\mathbf{2 a}$ and $\mathbf{3 a}$, while eosin- $Y$ in ethanol was used for the halogenated compounds $\mathbf{2} \mathbf{b}-\mathbf{c}$ and $\mathbf{3 b}$-c. Acetonitrile was used as the solvent for all dye samples. The absorbance for each dye and its corresponding standard were set to $\sim 0.1$ and recorded at the excitation wavelength. After excitation at this wavelength, the integration of the fluorescence was measured for both the dye and its standard.

Electrochemistry. Cyclic voltammetry experiments were conducted on an EG\&G PAR 263A potentiostat/galvanostat using a three-electrode cell comprising a Pt working electrode, a Pt wire auxiliary electrode, and a $\mathrm{Ag}$ wire reference electrode. For all measurements, samples were purged by bubbling nitrogen through the solution for $15 \mathrm{~min}$. Tetrabutylammonium hexafluorophosphate was used as the supporting electrolyte $(0.1 \mathrm{M})$ and ferrocene was added as an internal redox reference. All redox potentials were measured relative to the ferrocenium/ferrocene $\left(\mathrm{Fe}^{+} / \mathrm{Fe}\right)$ couple $(0.64 \mathrm{~V}$ vs. $\mathrm{NHE})$ used as an internal standard and then adjusted to NHE. ${ }^{19}$ Scans were performed at a scan rate of 100 $\mathrm{mV} \mathrm{s}^{-1}$. 
Crystal Growth and X-ray Structure Determination. Each compound was dissolved in a minimal amount of $\mathrm{CH}_{2} \mathrm{Cl}_{2}$ in a vial. After carefully adding a layer of hexanes to the vial, the solvent was allowed to slowly mix and evaporate over a period of a week, yielding suitable crystals.

Crystals were placed onto the tip of glass optical fibers and mounted on a Bruker SMART APEX II CCD Platform diffractometer for data collection at $100.0(1) \mathrm{K}^{20}$ For each crystal, a preliminary set of cell constants and an orientation matrix were calculated from reflections harvested from three orthogonal wedges of reciprocal space. The full data collections were carried out using MoK $\alpha$ radiation $(0.71073 \AA$, graphite monochromator) with frame times ranging from 15 to 45 seconds and a detector distance of approximately $4 \mathrm{~cm}$. Randomly oriented regions of reciprocal space were surveyed: five or six major sections of frames were collected with $0.50^{\circ}$ steps in $\omega$ at different $\phi$ settings and a detector position of -38 in $2 \theta$. The intensity data were corrected for absorption. ${ }^{21}$

Structures were solved using SHELXS-97 ${ }^{22}(\mathbf{2 c})$ or SIR97 $(\mathbf{2 a}, \mathbf{2 b}, \mathbf{3 c})^{23}$ and refined using SHELXL-97. ${ }^{22}$ Space groups were determined based solely on systematic absences (2a-2c) or a combination of systematic absences and intensity statistics (3c). Direct-methods solutions were calculated which provided most non-hydrogen atoms from the E-map. Full-matrix least squares / difference Fourier cycles were performed which located the remaining non-hydrogen atoms. All non-hydrogen atoms were refined with anisotropic displacement parameters. All hydrogen atoms were placed in ideal positions and refined as riding atoms with relative isotropic displacement parameters. Full matrix least squares refinements on $F^{2}$ were run to convergence. Final cell constants were calculated from the xyz centroids; the number of strong reflections are given in table S2 from the actual data collection after integration. ${ }^{24}$ See Table S1 for additional crystal and refinement information.

The angles between the pendant phenyl rings and the fused ring portions are $80.36(3), 89.14(5)$, 81.47(3), and 85.63(5) degrees, respectively, for structures $\mathbf{2 a}, \mathbf{2 b}, \mathbf{2 c}$, and $\mathbf{3 c}$. There are halogenhalogen close contacts in two of four structures. ${ }^{25,26}$ In $\mathbf{2} \mathbf{b}$ the Br...F intermolecular distance of 2.951(1) $\AA$ is $0.37 \AA$ shorter than the sum of the van der Waals radii and in $\mathbf{2 c}$ the I...F distance of $3.2464(8) \AA$ is 0.20 $\AA$ A shorter than the sum of the van der Waals radii. Despite having both fluorine and iodine, there are no halogen-halogen close contacts in $\mathbf{3 c}$.

Time-correlated Single Photon Counting. The sample, housed in a $1 \mathrm{~cm}$ cuvette, was pumped by a Fianium fiber laser, with 488-nm light selected by an acousto-optic tunable filter. Fluorescence was 
detected by an avalanche photodiode (Micro Photon Devices) coupled to a PicoHarp 300 (PicoQuant) time analyzer, using SymPhoTime software (PicoQuant).

Transient Absorption Spectroscopy. This setup has been described previously. ${ }^{27}$ Briefly, femtosecond pulses were produced by a regeneratively amplified titantium:sapphire laser (SpectraPhysics Spitfire) with a $1 \mathrm{kHz}$ repetition rate. The actinic pump was generated from a home-built noncollinear optical parametric amplifier. The probe was created by focusing an $800-\mathrm{nm}$ beam through a calcium fluoride crystal, generating a white light continuum between $325-650 \mathrm{~nm}$. A blue color filter (Schott BG40) was used to eliminate the residual $800 \mathrm{~nm}$ beam before the detector. The actinic pump, $530 \mathrm{~nm}$, was kept near $70 \mathrm{~nJ} /$ pulse, with beam diameters of $\sim 70 \mu \mathrm{m}$ and time resolution of $\sim 200 \mathrm{fs}$. The time delay was adjusted by optically delaying the pump pulse, with time steps increasing logarithmically. ${ }^{28}$ Every other pump pulse was blocked by a chopper, with each probe pulse measured by a CCD (Princeton Instruments, Pixis, 100BR) after being dispersed by a grating spectrograph (Acton, 150 $\mathrm{gr} / \mathrm{mm}$ ). Samples were held in a 1-mm cuvette and translated to ensure replenishment of the illuminated volume. The software program Igor Pro (Wavemetrics) was used to fit the kinetic traces to the convolution of the Gaussian instrument response and an exponential. Stated errors in the fit parameters are $1 \sigma$.

Hydrogen Evolution Experiments. Photolysis experiments were run with broad band irradiation using a $200 \mathrm{~W}$ Xe/Hg lamp equipped with a cutoff filter $(\lambda>410 \mathrm{~nm})$. Samples were prepared in $16 \mathrm{~mL}$ test tubes. The catalyst and dye were dissolved in a total of $4 \mathrm{~mL}$ of acetonitrile $/ \mathrm{H}_{2} \mathrm{O} 1: 1$ with $5 \%$ $\mathrm{TEOA}_{\mathrm{aq}}$. The TEOA $\mathrm{aq}$ solution was adjusted to $\mathrm{pH} 7$ by addition of conc. $\mathrm{HCl}$. Test tubes were sealed with septa and copper wire and purged with $\mathrm{N}_{2}$ for $10 \mathrm{~min}$. After removing $1 \mathrm{~mL}$ of the $\mathrm{N}_{2}$ atmosphere at ambient pressure, $1 \mathrm{~mL}$ of methane at ca. 1 atm was added, for use as an internal standard for GC measurements. The samples were placed on a rotating 6-test tube apparatus and irradiated while stirring. The intensity of the bulb at the distance of the test tube sample was determined to be approximately $930 \mathrm{~W} / \mathrm{m}^{2}$. Hydrogen production was monitored by gas chromatography (Shimadzu GC17A) with a TCD detector on a $30 \mathrm{~m}$ molecular sieve column using an $\mathrm{N}_{2}$ carrier gas.

Computations. Calculations were run using Gaussian 09. ${ }^{29}$ Optimized geometries were obtained using DFT, with the hybrid functional B3LYP. ${ }^{30}$ The basis set $6-31++G(d, p)^{31,32}$ was used for all atoms except iodine, for which $3-21 \mathrm{G}^{33}$ was used. The solvent acetonitrile was modeled using a polarizable continuum model. ${ }^{34}$ TD-DFT was used to calculate excitation energies. ${ }^{35}$ The Molden software package was used to display the frontier orbitals. ${ }^{36}$ 


\section{Results}

The catalyst (1) and photosensitizers (series $\mathbf{2}$ and $\mathbf{3}$ ) examined in this study, shown in Figure 1, were synthesized following general procedures from the literature. ${ }^{4}$ Briefly, the parent compounds $\mathbf{2 a}$ and 3a were synthesized by condensation of 2,4-dimethylpyrrole and the appropriate aryl aldehyde (benzaldehyde or mesitaldehyde) in a 2:1 ratio, followed by oxidation employing 2,3-dichloro-5,6dicyanobenzoquinone (DDQ) and reaction with base and $\mathrm{BF}_{3}-\mathrm{OEt}_{2}{ }^{37}$ For bromination reactions, the precursor (2a or $\mathbf{3 a}$ ), N-bromosuccinimide (NBS), and azobisisobutyronitrile (AIBN) were dissolved in benzene and heated at reflux for $40 \mathrm{~min}$. lodination reactions were carried out by dissolving the precursor, $\mathrm{I}_{2}$, and $\mathrm{HIO}_{3}(\mathrm{aq})$ in ethanol and heating at $60{ }^{\circ} \mathrm{C}$ for $20 \mathrm{~min} .{ }^{38}$ These compounds were characterized by NMR, UV-Vis and emission spectroscopies, elemental analyses, cyclic voltammetry, Xray crystallography, time-correlated single photon counting and femtosecond transient absorption spectroscopy.
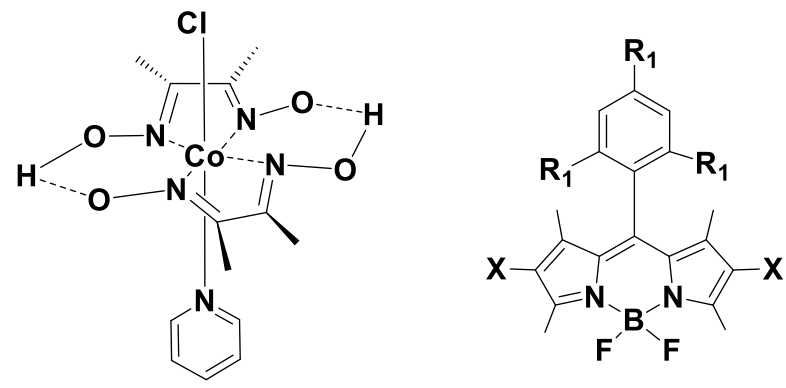

1 2a: $X=H, R_{1}=H \quad$ 3a: $X=H, R_{1}=C_{3}$

2b: $X=B r, R_{1}=H$ 3b: $X=B r, R_{1}=C_{3}$

2c: $X=I, R_{1}=H \quad 3 c: X=I, R_{1}=C_{3}$

Figure 1: Structures of the catalyst and chromophores used in this study.

As shown, replacement of the phenyl substituent of series $\mathbf{2}$ with a mesityl substituent (as in series 3) does not significantly alter the absorption and emission maxima of the dyes. It does, however, increase both their fluorescence quantum yields and molar absorptivities. The addition of a halogen (where $\mathrm{X}=\mathrm{Br}, \mathrm{I}$ ) results in absorption and emission energies that are shifted to lower energy, and both the fluorescent lifetimes and quantum yields decrease. Figure 2 shows the absorption and emission spectra for $\mathbf{2 a - c .}$ 
Table 1. Photophysical data for six BODIPY photosensitizers in acetonitrile.

\begin{tabular}{cccccc}
\hline Chromophore & $\lambda_{\text {abs,max }}(\mathrm{nm})$ & $\lambda_{\mathrm{em}, \max }(\mathrm{nm})$ & $\Phi_{\mathrm{fl}}$ & $\tau(\mathrm{ps})$ & $\varepsilon\left(\mathbf{M}^{-1} \mathrm{~cm}^{-1}\right)$ \\
\hline 2a & 497 & 507 & $0.60^{\mathrm{a}}$ & $3550(10)^{\mathrm{c}}$ & 58,800 \\
2b & 522 & 538 & $0.158^{\mathrm{b}}$ & $1465(2)^{\mathrm{c}}$ & 67,900 \\
2c & 528 & 546 & $0.018^{\mathrm{b}}$ & $124(4)^{\mathrm{d}}$ & 68,500 \\
3a & 498 & 508 & $0.939^{\mathrm{a}}$ & $6010(50)^{\mathrm{c}}$ & 82,400 \\
3b & 524 & 538 & $0.213^{\mathrm{b}}$ & $1550(10)^{\mathrm{c}}$ & 72,600 \\
3c & 530 & 547 & $0.021^{\mathrm{b}}$ & $132(3)^{\mathrm{d}}$ & 77,400
\end{tabular}

${ }^{\text {a }}$ Calculated based on fluorescein reference $\left(\Phi_{\mathrm{fl}}=0.95\right.$ in $\left.0.1 \mathrm{M} \mathrm{NaOH}_{\mathrm{aq}}\right) .{ }^{\mathrm{b}}$ Calculated based on Eosin-Y reference $\left(\Phi_{\mathrm{fl}}=0.45\right.$ in ethanol). ${ }^{\mathrm{c}}$ Obtained from time-correlated single photon counting. ${ }^{\mathrm{d}}$ Obtained from transient absorption spectroscopy.

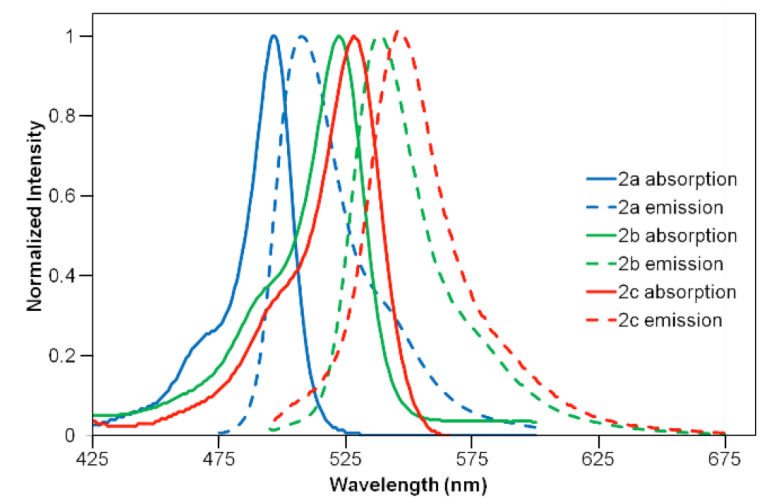

Figure 2: Normalized absorption (solid) and emission (dashed) spectra of series $\mathbf{2}$ photosensitizers.

The oxidation and reduction potentials of the photosensitizers were determined via cyclic voltammetry and are displayed in Table 2. As observed with other Bodipy chromophores, ${ }^{16}$ all compounds exhibit irreversible oxidations and reversible reductions. The redox potentials for the phenyl derivatives of series $\mathbf{2}$ are almost identical to those of their mesityl counterparts. The oxidation potentials of the halogenated derivatives are more positive than the parent compounds, while the reduction potentials of the halogenated derivatives are less negative than the parent compound. This correlates with the electron withdrawing effect of the halogen substituents, as the electronegative 
halogens make the Bodipy core more electron deficient, resulting in more positive oxidation potentials and less negative reduction potentials.

Table 2. Electrochemical data for photosensitizers 2a-c and 3a-c.

\begin{tabular}{ccc}
\hline Chromophore & Oxidation $^{\mathrm{a}} \mathbf{E}(\mathrm{V})$ & Reduction $^{\mathrm{b}} \mathrm{E}_{\mathbf{1 / 2}}(\mathrm{V})$ \\
\hline $\mathbf{2 a}$ & 1.42 & -0.92 \\
$\mathbf{2 b}$ & 1.58 & -0.64 \\
$\mathbf{2 c}$ & 1.53 & -0.66 \\
3a & 1.42 & -0.93 \\
3b & 1.61 & -0.64 \\
3c & 1.52 & -0.67 \\
\hline
\end{tabular}

${ }^{a}$ irreversible oxidation peak estimated vs. $\mathrm{NHE}$ in $\mathrm{MeCN}$ using $\mathrm{Fc}^{+/ 0}$ as an internal standard; ${ }^{b}$ reversible reduction potential vs. NHE in MeCN using $\mathrm{Fe}^{+/ 0}$ as an internal standard. $\Delta \mathrm{E}_{\mathrm{p}} \sim 80 \mathrm{mV}$ for $\mathrm{Fc}^{+/ 0}$ and between $80-90 \mathrm{mV}$ for reductions of Bodipy chromophores

The solid-state structures of $\mathbf{2 a - c}$ and $\mathbf{3 c}$ were determined using single-crystal X-ray crystallography. ORTEP diagrams are shown in Figure S1. Crystal structure, data collection, and structure refinement data are given in Table S1. Selected bond lengths, angles and torsions are given in Table S2. Comparing 2a to its halogenated analogues, $\mathbf{2} \mathbf{b}$ and $\mathbf{2 c}$, only a minimal change in the BODIPY structure is observed, with the dipyrrole rings nearly planar. For the structures of $2 a-c$ the dihedral angle between the phenyl ring and the dipyrrole ring ranges from $82-90^{\circ}$. A comparison of the structures of $\mathbf{2 c}$ and $3 \mathrm{c}$ reveals that the mesityl-substituent does not greatly alter the solid state structure. The torsion angle between the pyrrole rings and the phenyl substituent for $2 \mathrm{c}$ is $97.9(1)^{\circ}$ while in $3 \mathrm{c}$ it is $93.3(2)^{\circ}$.

Based on DFT calculations, the optimized geometries of compounds 2a-c are shown in Figure 3, as well as diagrams of the HOMO and LUMO for each. As in the crystal structures, the addition of the halogens in $\mathbf{2 b}$ and $\mathbf{2} \mathbf{c}$ do not significantly alter the optimized geometry. The majority of the HOMO $\pi$ orbitals and the LUMO $\pi^{*}$ orbitals lie on the conjugated Bodipy core, consistent with similar dyes. ${ }^{5}$ The energy level of the HOMO and LUMO are stabilized by halogenation, more in Br-substituted $\mathbf{2} \mathbf{b}$ than in Isubstituted 2c. Based on time-dependent density functional calculations (TD-DFT) the lowest energy singlet transition for $\mathbf{2 a}$ is $431 \mathrm{~nm}(2.88 \mathrm{eV})$ while $\mathbf{2 b}$ and $\mathbf{2 c}$ are at lower energies of $453 \mathrm{~nm}(2.73 \mathrm{eV})$ and $463 \mathrm{~nm}(2.68 \mathrm{eV})$, obtained with a polarizable continuum model of acetonitrile. The overestimation of the calculated transition energies is common for DFT studies of Bodipy dyes. ${ }^{5,39}$ As with a similar series, $^{5}$ the trend found for the calculated lowest energy singlet transitions upon halogenation is consistent with what is observed experimentally. 


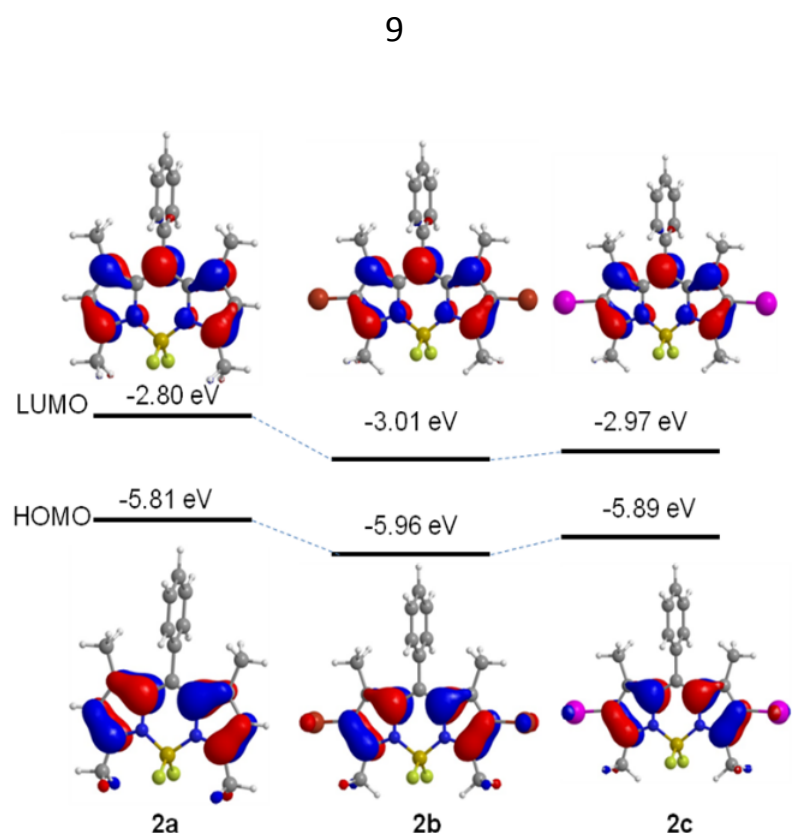

Figure 3: HOMO and LUMO energy levels for 2a-c molecular orbital diagrams.

In order to test the ability of series $\mathbf{2}$ and $\mathbf{3}$ to act as photosensitizers for hydrogen production, a series of photolysis experiments were performed. Initially, irradiation $(\lambda>455 \mathrm{~nm})$ for 50 hours of $4 \mathrm{~mL}$ solutions in 1:1 MeCN:( $\left.\mathrm{H}_{2} \mathrm{O} / \mathrm{TEOA}, 9: 1: \mathrm{v} / \mathrm{v}\right)$ containing $5.0 \times 10^{-5} \mathrm{M} 2 \mathrm{a}$ or $3 \mathrm{a}$, and $1.0 \times 10^{-4} 1$ catalyst did not lead to the detection of $\mathrm{H}_{2}$. However, both the brominated and iodinated derivatives $\mathbf{2 b}, \mathbf{2 c}$ and $\mathbf{3 b}$, 3c, were found to function as photosensitizers for the photoreduction of water. In order to compare the phenyl- and mesityl-substituted photosensitizers for hydrogen production, all four of the halogenated derivatives were irradiated $(\lambda>410 \mathrm{~nm})$ under identical conditions (Figure 4). The results show negligible differences in $\mathrm{H}_{2}$ production between $\mathbf{2} \mathbf{b}$ and $\mathbf{2 c}$, but a significant difference was seen in hydrogen production between $\mathbf{3} \mathbf{b}$ and $\mathbf{3 c}$. With $\mathbf{2} \mathbf{b}$ or $\mathbf{2} \mathbf{c}$ as the photosensitizer, the system bleaches after $5 \mathrm{~h}$ and ceases hydrogen production. While the initial rates of $\mathrm{H}_{2}$ production for the mesitylsubstituted PSs $\mathbf{3} \mathbf{b}$ and $\mathbf{3} \mathbf{c}$ are similar to those seen for $\mathbf{2} \mathbf{b}$ and $\mathbf{2} \mathbf{c}$, they eventually produce more hydrogen than do the phenyl-substituted PSs as a result of greater system longevity. 


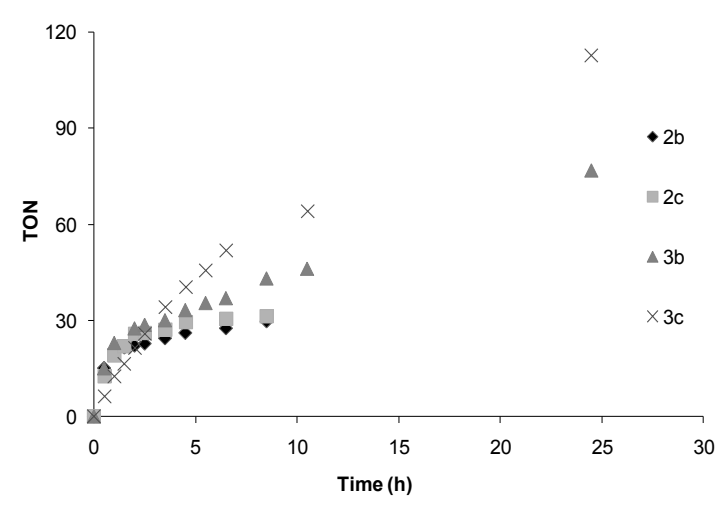

Figure 4: Hydrogen production results for $\mathbf{2 b - c}$ and $3 \mathbf{b}-\mathrm{c}$ with dye concentration of $5.0 \times 10^{-5} \mathrm{M}$ and catalyst concentration of $1.0 \times 10^{-4} \mathrm{M}$ in 1:1 MeCN:10\% TEOA(aq) irradiated by $\lambda>410 \mathrm{~nm}$ light. Turnover number (TON) represents moles of hydrogen produced versus moles of photosensitizer.

As shown in Figure 5, both the concentration of dye and catalyst were varied in order to optimize the system. At lower catalyst concentrations in Fig. 5a, the system becomes catalyst turn-over limited, and hydrogen production does not occur as efficiently. Additionally, lower catalyst concentrations are associated with faster photosensitizer bleaching because of the longer lifetimes of the radical anion of the photosensitizer, $\mathrm{PS}^{\circ}$, prior to electron transfer to the catalyst. ${ }^{11}$ At high catalyst concentrations, induction periods occur before hydrogen production commences. As we have described previously, during the induction period all of the Co[III] catalyst is converted to Co[II] catalyst, at which point hydrogen production can commence with subsequent photoinduced electron transfer events. ${ }^{9,40}$ Interestingly, the catalyst concentration dependence shows a sharp peak, indicating that the catalyst concentration needs to be carefully tuned to the given illumination intensity and PS concentration. When the concentration of catalyst is too low, the slower bimolecular kinetics of the electron transfer from PS•- to the catalyst cause enhanced photodegradation of PS•-. At higher catalyst concentrations, the induction period limits the time they system spends in the productive phase of hydrogen production.

When varying the PS concentration in Fig. $5 b, \mathrm{H}_{2}$ production increased with increasing PS concentration but plateaued at $\sim 1.4 \mathrm{ml}$ (58 micromoles) at [PS] greater than $\sim 60$ microM, i.e. at PS concentrations greater than approximately half the catalyst concentration. However, the highest TON with respect to chromophore of 670 was obtained with concentrations of $5 \times 10^{-6} \mathrm{M}$ for $3 \mathrm{c}$ and $1.0 \times 10^{-4}$ $M$ for 1, i.e. a 20-fold excess of catalyst over sensitizer. Low concentrations of photosensitizers cause inefficent absorption of light leading to lower yields of hydrogen. While increasing the amount of 
chromophore does lead to the generation of a greater amount of hydrogen, the actual TON with respect to photosensitizer decreases, due to the smaller penetration depth of light into the vial and the increased likelihood of photobleaching of the $\mathrm{PS}^{\circ}$ species formed by photo-reduction of PS by TEOA. In other words, when the ratio of catalyst to PS is quite large, there is a lower probability that the PS will degrade while in the $\mathrm{PS}^{\bullet-}$ state because of the faster kinetics of the $\mathrm{PS}^{\bullet-}+\mathrm{Co}[\mathrm{n}] \rightarrow \mathrm{PS}+\mathrm{Co}[\mathrm{n}-1]$ reaction.
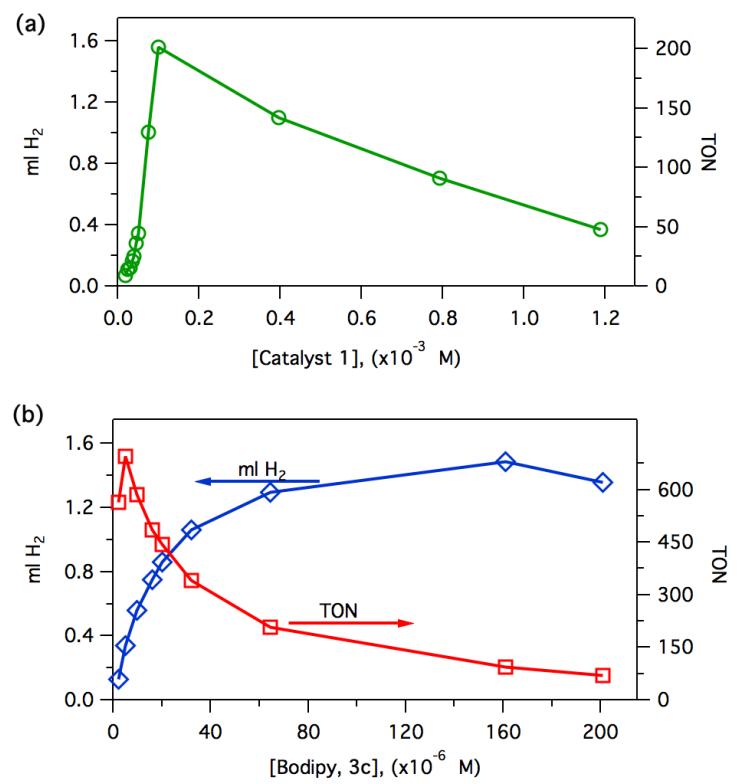

Figure 5: The total amount of evolved hydrogen for (a) varying concentrations of catalyst $\mathbf{1}$ with a fixed concentration of photosensitizer $3 \mathrm{c}\left(8.0 \times 10^{-5} \mathrm{M}\right)$, and for $(\mathrm{b})$ varying concentrations of photosensitizer $3 \mathrm{c}$ with a fixed concentration of catalyst $1\left(1.0 \times 10^{-4} \mathrm{M}\right)$. In each case, TON is calculated relative to photosensitizer concentration. Hence, in (a) the two vertical axes, $\mathrm{ml} \mathrm{H}_{2}$ and TON, are proportional to each other, whereas in (b) the varying concentrations of photosensitizer produce a TON (red, right hand axis) dependence that is very different than the total $\mathrm{ml} \mathrm{H}_{2}$ produced (blue, left hand axis).

\section{Discussion}

Effect of Halogenation. As in previous studies, bromination and iodination of Bodipy chromophores increases the rate of intersystem crossing from the initially excited ${ }^{1} \pi \pi^{*}$ state, thus generating greater amounts of ${ }^{3} \pi \pi^{*}$ state. ${ }^{5}$ The triplet excited state is much longer-lived than the corresponding singlet state, thereby allowing diffusion-controlled bimolecular interactions to occur more substantially. The absorption and emission spectra both shift to lower energy upon halogenation, 
reflecting changes in the relative energies of the LUMO and HOMO that was evidenced via electrochemistry. The DFT calculations are also consistent with the electrochemistry, showing that both frontier orbitals decrease in energy upon halogenation, presumably stabilized by the electron withdrawing nature of the halogens. In terms of hydrogen production, only halogenated dyes are active, owing to their long-lived excited triplet states. This is consistent with previous studies of bimolecular electron transfer. ${ }^{5}$

Effect of Phenyl vs Mesityl. The phenyl and mesityl derivatives display mostly similar characteristics, including absorption and emission energies, redox potentials, and nature of frontier orbitals. The molar absorptivities are consistently higher with the mesityl derivatives, but only by 5-20\%. The differences between the quantum yields and lifetimes of $\mathbf{2 a}$ and $3 a$ are more significant, from 0.60 to 0.939 and 3550 ps to 6010 ps, respectively. These changes correlate with the steric hindrance imposed by the mesityl group, where the two ortho-substituted methyl groups inhibit rotation about the Bodipy core. By restricting this torsional motion, the rate of internal conversion corresponding to non-radiative decay decreases, prolonging the excited state lifetime of $\mathbf{3 a}$ relative to $\mathbf{2} \mathbf{a}$, and increasing its fluorescence quantum yield. In theory, this should make 3a superior to $2 \mathbf{a}$ in terms of hydrogen production, as the excited state of 3a lives longer and can thus interact with another species. In practice, however, the singlet states of both dyes decay faster than the rate of bimolecular electron transfer in the system, and no hydrogen is produced.

Hydrogen production is observed in systems containing the halogenated Bodipy dyes, with no real difference in the initial rates of $\mathrm{H}_{2}$ production between systems having dyes with phenyl and mesityl substituents. Unlike the parent compounds, the fluorescence lifetimes of the brominated phenyl and mesityl dyes are very similar (1465 ps to 1550 ps, respectively), as are the iodinated phenyl and mesityl dyes (124 ps to 132 ps). Rather than revealing information about the rate of internal conversion, the time constants associated with these dyes reveal the rate of intersystem crossing, which is dependent on spin-orbit coupling and vibrational overlap, but not the torsional motion of the chromophore. The difference in facility of torsional motion between phenyl and mesityl therefore has no effect on the rate of intersystem crossing from the singlet to triplet manifold. In that same sense, the triplet lifetimes of the phenyl and mesityl dyes should not differ significantly, resulting in similar initial rates of activity for the photogeneration of $\mathrm{H}_{2}$.

The total amount of $\mathrm{H}_{2}$ produced, however, is influenced by the choice of substituent. In both the brominated and iodinated dyes, the systems containing the mesityl derivatives remain active longer 
than systems containing the phenyl derivatives. Similar effects have been observed for Bodipy cobaloxime dyads, where functional groups increasing the basicity of the aryl group have led to increased stability in the dyads. ${ }^{13,16}$ Due to the donating ability of the methyl groups, the mesityl group is more basic than the phenyl, and thus systems containing mesityl derivatives are more robust than those with phenyl derivatives. The effect of mesityl versus phenyl as a Bodipy substituent thus appears to be electronic in origin rather than steric. Another conclusion based on the rates and duration of $\mathrm{H}_{2}$ production is that the system with $\mathbf{3 c}$ as PS appears more stable than that with $\mathbf{3 b}$, suggesting that the iodinated dye is also more robust than the corresponding brominated derivative. The enhanced stability of an iodinated derivative versus a brominated derivative has also been seen in our previous work. ${ }^{5}$

Note that, during preparation of this manuscript, Luo et al. published a paper exploring the efficacy of $\mathrm{COOH}$ substituted phenyl groups on the Bodipy chromophore. ${ }^{18}$ Luo's bimolecular system is also run at a very high chromophore concentration but has TONs of 200, lower than our values presumably due to the large concentration of dye.

Perspective on systems containing unlinked components relative to those having tethered catalyst-chromophore dyads. In the last year, several articles have been published describing dyads containing a Bodipy chromophore and the cobaloxime catalyst 1 or closely related derivatives, as shown in Figure $6 .{ }^{13-17}$ In these systems, the aryl substituent linked to the Bodipy core is a pyridyl group, which allows facile connection to the cobaloxime catalyst with the derivatized pyridine binding to the Co ion as the axial ligand. The systems were found to be effective for the light-driven generation of $\mathrm{H}_{2}$ only when the Bodipy dye contains bromine or iodine substituents, indicating the importance of accessing the longlived ${ }^{3} \pi \pi^{*}$ state of the dye for photoinduced electron transfer. ${ }^{14,15}$ Studies indicate that a free cobaloxime catalyst does not quench the fluorescence of the Bodipy, ${ }^{18}$ but that a cobaloxime linked through the pyridine will, although it will not go on to produce hydrogen without the presence of a halogenated Bodipy. ${ }^{14}$

Much discussion in the literature has centered on the effectiveness of chromophore - catalyst dyad constructs. ${ }^{41-44}$ One benefit is that covalent attachment can increase the rate of electron transfer to the catalyst, as the process is no longer controlled by diffusion. However, such a construct will also facilitate back electron transfer so that the benefit of faster forward electron transfer may be negated. Additionally, attachment of the chromophore to the cobaloxime catalyst via a derivatized pyridine ligand presents its own problems. Specifically, the lability of ligands on Co when it is reduced to the Co(II) state is well established in coordination chemistry, and has been shown specifically for systems in which $\mathbf{1}$ is 
used as a catalyst. ${ }^{42}$ In this earlier study, it was demonstrated that the pyridine ligand coordinated to Co in 1 readily exchanges with a derivatized pyridine in aqueous acetonitrile upon Co(II) formation. Moreover, under $\mathrm{H}_{2}$ generating conditions, it was determined that the glyoxime ligands of $\mathbf{1}$ also undergo exchange. The consequence of these results is that catalyst $\mathbf{1}$ and its derivatives with functionalized pyridines possess little structural integrity during the course of hydrogen generation with TEOA as sacrificial donor and a reaction medium containing water. ${ }^{42}$ This has been shown clearly in previous experiments by Manton et al. ${ }^{14}$

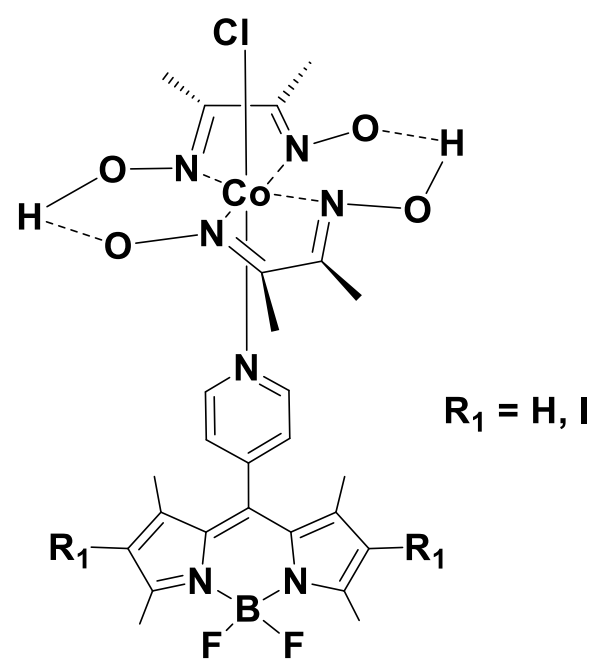

Figure 6: Example of Bodipy - cobaloxime dyad from Reference 16.

In the 2014 report using Bodipy-cobaloxime dyads for the photogeneration of $\mathrm{H}_{2}{ }^{16}$ the activity of making $\mathrm{H}_{2}$ from aqueous protons was said to be a direct consequence of the integrity of the catalystphotosensitizer dyad. This assertion was based on a comparison between two systems, one containing the intact dyad, and the other containing Co catalyst $\mathbf{1}$ and a Bodipy dye in which the pyridine moiety in the meso position of the dye is $\mathrm{N}$-methylated. The latter showed minimal $\mathrm{H}_{2}$ generation relative to the former. While $\mathrm{N}$-methylation of the pyridine does prevent its coordination to the Co ion, thus ensuring only "bimolecular" electron transfer, it introduces another factor that negates the value of the control experiment. Specifically, $\mathrm{N}$-alkylated pyridines can serve as electron acceptors, ${ }^{45,46}$ rapidly quenching the singlet or triplet PS* state intramolecularly and preventing electron transfer to the catalyst. The control experiment thus introduced an alternative reaction path - forward electron transfer from Bodipy* to the $\mathrm{N}$-Me pyridinium moiety followed by back electron transfer to ground state - that prevents hydrogen production. 
Recently, Luo et al. described another Bodipy-cobaloxime dyad with a meta-substituted pyridine on the Bodipy and halogenated thienyl groups at the R1 positions (Fig. 6). ${ }^{17}$ Luo et al. support the hypothesis that the system proceeds through reductive quenching from PS* to PS but also that the binding of sensitizer and catalyst is critical to system performance. The induction period and $\mathrm{pH}$ dependence observed in their systems is consistent with our previous observations. ${ }^{40}$ The observed difference in performance between the dyad reported by Luo, at al., and the analogous system composed of individual components is quite small given the large variation in productivity of different Cobaloxime catalysts. ${ }^{40}$ Most importantly, as stated above, the $\mathrm{CoCl}(\mathrm{pyr})(\mathrm{dmgH})_{2}$ part of the system undergoes ligand exchange upon reduction in aqueous acetonitrile, eliminating the possibility for stability of the dyad. ${ }^{42}$

One further point regarding the effectiveness of dyads having an organic photosensitizer and the cobaloxime catalyst exemplified by 1 needs to be made. ${ }^{10,11,17}$ It is evident that such systems can (and likely do) function by the reductive quenching of the excited photosensitizer (PS*) by the electron donor (TEOA) to form $\mathrm{PS}^{-}$rather than by oxidative quenching with electron transfer from $\mathrm{PS}^{*}$ to the catalyst. The concentrations of sacrificial donor in these systems is generally $10^{3}-10^{4}$ times greater than that of the catalyst, making the reductive quenching path that which is followed if oxidative and reductive quenching rate constants do not differ by more than a factor of $10^{2}$. Making structurally stable dyads represents an effort to bias systems containing them to oxidative quenching by photoinduced electron transfer to the catalyst. However, the stability of the hypothesized photogenerated charge-separated state, i.e. $\mathrm{Co}^{\prime \prime}-\mathrm{Bodipy}^{(+)}$, on the time scale of the reaction with the sacrificial donor has not been demonstrated. Most importantly, cycling of the catalyst through several oxidation states, of which one or more may be labile, proves problematic in this approach.

\section{Conclusion}

A series of Bodipy chromophores were used as light harvesters in a system containing the Co(dmg) catalyst 1 and TEOA as the sacrificial electron donor in aqueous organic media. Both the bromine and iodine substituents on Bodipy are effective for light-driven $\mathrm{H}_{2}$ production by facilitating intersystem crossing to the long-lived ${ }^{3} \pi \pi^{*}$ state for photoinduced electron transfer. A mesityl group was found to be preferable to a phenyl group on the Bodipy meso position in terms of increasing dye stability and system durability for hydrogen generation. The maximum turnover number of $\sim 700$ relative to photosensitizer is obtained under optimal conditions over $30 \mathrm{~h}$. The activity of this system is greater than that of similar Bodipy - Co(dmg) dyads recently published, indicating that these nominal dyads do 
not remain intact upon photolysis. The present results, along with related reports, underscore the importance of knowing the primary photochemical step and subsequent electron and proton transfers in the construction of active and durable systems for the photogeneration of hydrogen from aqueous protons.

Associated Content. Supporting Information Available: Synthetic procedures, X-ray crystallography technical details and results (CCDC 1406900-1406903), femtosecond transient absorption kinetics, as well as X-ray structure CIF files. This material is available free of charge via the Internet at http://pubs.acs.org.

Author Information.

*Corresponding Authors: mccamant@chem.rochester.edu, eisenberg@chem.rochester.edu

Acknowledgments. We are grateful to Ben Martin and Lewis Rothberg for their assistance with the TCSPC measurements. This work was supported by a National Science Foundation Collaborative Research grant, CHE-1151789. Additionally, DWM was supported as an Alfred P. Sloan Research Fellow and RPS was supported by a National Science Foundation Graduate Research Fellowship. 
(1) Lewis, N.S.; Nocera, D.G. Powering the Planet: Chemical Challenges in Solar Energy Utilization. Proc. Natl. Acad. Sci. U. S. A. 2006, 103, 15729-15735.

(2) Ziessel, R.; Ulrich, G.; Harriman, A. The Chemistry of Bodipy: A New El Dorado for Fluorescence Tools. New J. Chem. 2007, 31, 496-501.

(3) Ulrich, G.; Ziessel, R.; Harriman, A. The Chemistry of Fluorescent Bodipy Dyes: Versatility Unsurpassed13. Angew. Chem. 2008, 47, 1184-1201.

(4) Loudet, A.; Burgess, K. Bodipy Dyes and Their Derivatives: Syntheses and Spectroscopic Properties. Chem. Rev. 2007, 107, 4891-4932.

(5) Sabatini, R.P.; McCormick, T.M.; Lazarides, T.; Wilson, K.C.; Eisenberg, R.; McCamant, D.W. Intersystem Crossing in Halogenated Bodipy Chromophores Used for Solar Hydrogen Production. J. Phys. Chem. Lett. 2011, 2, 223-227.

(6) Yamada, K.; Toyota, T.; Takakura, K.; Ishimaru, M.; Sugawara, T. Preparation of Bodipy Probes for Multicolor Fluorescence Imaging Studies of Membrane Dynamics. New J. Chem. 2001, 25, 667-669.

(7) Hu, X.; Cossairt, B.M.; Brunschwig, B.S.; Lewis, N.S.; Peters, J.C. Electrocatalytic Hydrogen Evolution by Cobalt Difluoroboryl-Diglyoximate Complexes. Chem. Comm. 2005, 4723-4725.

(8) Hu, X.; Brunschwig, B.S.; Peters, J.C. Electrocatalytic Hydrogen Evolution at Low Overpotentials by Cobalt Macrocyclic Glyoxime and Tetraimine Complexes. J. Am. Chem. Soc. 2007, 129, 89888998.

(9) Du, P.; Knowles, K.; Eisenberg, R. A Homogeneous System for the Photogeneration of Hydrogen from Water Based on a Platinum(li) Terpyridyl Acetylide Chromophore and a Molecular Cobalt Catalyst. J. Am. Chem. Soc. 2008, 130, 12576-12577.

(10) Lazarides, T.; McCormick, T.; Du, P.; Luo, G.; Lindley, B.; Eisenberg, R. Making Hydrogen from Water Using a Homogeneous System without Noble Metals. J. Am. Chem. Soc. 2009, 131, 91929194.

(11) McCormick, T.M.; Calitree, B.D.; Orchard, A.; Kraut, N.D.; Bright, F.V.; Detty, M.R.; Eisenberg, R. Reductive Side of Water Splitting in Artificial Photosynthesis: New Homogeneous Photosystems of Great Activity and Mechanistic Insight. J. Am. Chem. Soc. 2010, 132, 15480-15483.

(12) Lazorski, M.S.; Castellano, F.N. Advances in the Light Conversion Properties of Cu(I)-Based Photosensitizers. Polyhedron 2014, 82, 57-70.

(13) Bartelmess, J.; Weare, W.W.; Sommer, R.D. Synthesis, Characterization and Structural Investigation of Novel Meso-Pyridyl Bodipy-Cobaloxime Complexes. Dalton Trans. 2013, 42, 14883-14891.

(14) Manton, J.C.; Long, C.; Vos, J.G.; Pryce, M.T. A Photo- and Electrochemical Investigation of Bodipy-Cobaloxime Complexes for Hydrogen Production, Coupled with Quantum Chemical Calculations. Phys. Chem. Chem. Phys. 2014, 16, 5229-5236.

(15) Luo, G.-G.; Fang, K.; Wu, J.-H.; Dai, J.-C.; Zhao, Q.-H. Noble-Metal-Free Bodipy-Cobaloxime Photocatalysts for Visible-Light-Driven Hydrogen Production. Phys. Chem. Chem. Phys. 2014, 16, 23884-23894.

(16) Bartelmess, J.; Francis, A.J.; El Roz, K.A.; Castellano, F.N.; Weare, W.W.; Sommer, R.D. LightDriven Hydrogen Evolution by Bodipy-Sensitized Cobaloxime Catalysts. Inorg. Chem. 2014, 53, 4527-4534. 
(17) Luo, G.-G.; Fang, K.; Wu, J.; Mo, J. Photocatalytic Water Reduction from a Noble-Metal-Free Molecular Dyad Based on a Thienyl-Expanded Bodipy Photosensitizer. Chem. Comm. 2015, 51, 12361-12364.

(18) Luo, G.-G.; Lu, H.; Zhang, X.-L.; Dai, J.-C.; Wu, J.-H.; Wu, J.-J. The Relationship between the Boron Dipyrromethene (Bodipy) Structure and the Effectiveness of Homogeneous and Heterogeneous Solar Hydrogen-Generating Systems as Well as Dsscs. Phys. Chem. Chem. Phys. 2015, 17, 97169729.

(19) Connelly, N.G.; Geiger, W.E. Chem. Rev. 1996, 96, 877-910.

(20) APEX2, version 2009.9-0; Bruker AXS: Madison, WI, 2009.

(21) Sheldrick, G.M. SADABS, version 2008/1; University of Göttingen: Göttingen, Germany, 2008.

(22) Sheldrick, G. A Short History of Shelx. Acta Crystallographica Section A 2008, 64, 112-122.

(23) Altomare, A.; Burla, M. C.; Camalli, M.; Cascarano, G. L.; Giacovazzo, C.; Guagliardi, A.; Moliterni, A. G. G.; Polidori, G.; Spagna, R. SIR97: A New Program for Solving and Refining Crystal Structures; Istituto di Cristallografia, CNR: Bari, Italy, 1999.

(24) SAINT, version 7.68A; Bruker AXS: Madison, WI, 2009.

(25) Awwadi, F.F.; Willett, R.D.; Peterson, K.A.; Twamley, B. The Nature of Halogen... Halogen Synthons: Crystallographic and Theoretical Studies. Chemistry Eur. J. 2006, 12, 8952-8960.

(26) Mukherjee, A.; Desiraju, G.R. Halogen Bonds in Some Dihalogenated Phenols: Applications to Crystal Engineering. IUCrJ 2014, 1, 49-60.

(27) Sabatini, R.P.; Zheng, B.; Fu, W.-F.; Mark, D.J.; Mark, M.F.; Hillenbrand, E.A.; Eisenberg, R.; McCamant, D.W. Deactivating Unproductive Pathways in Multichromophoric Sensitizers. J. Phys. Chem. A 2014, 118, 10663-10672.

(28) Megerle, U.; Pugliesi, I.; Schriever, C.; Sailer, C.F.; Riedle, E. Sub-50 Fs Broadband Absorption Spectroscopy with Tunable Excitation: Putting the Analysis of Ultrafast Molecular Dynamics On solid Ground. Appl. Phys. B 2009, 96, 215-231.

(29) Frisch, M.J.; Trucks, G.W.; Schlegel, H.B.; Scuseria, G.E.; Robb, M.A.; Cheeseman, J.R.; Scalmani, G.; Barone, V.; Mennucci, B.; Petersson, G.A.et al. Gaussian 09, Gaussian, Inc., Wallingford, CT, USA, 2009.

(30) Becke, A.D. Density-Functional Thermochemistry .3. The Role of Exact Exchange. J. Chem. Phys. 1993, 98, 5648-5652.

(31) Frisch, M.J.; Pople, J.A.; Binkley, J.S. Self-Consistent Molecular Orbital Methods 25. Supplementary Functions for Gaussian Basis Sets. J. Chem. Phys. 1984, 80, 3265-3269.

(32) Hehre, W.J.; Ditchfield, R.; Pople, J.A. Self-Consistent Molecular Orbital Methods. Xii. Further Extensions of Gaussian-Type Basis Sets for Use in Molecular Orbital Studies of Organic Molecules. J. Chem. Phys. 1972, 56, 2257-2261.

(33) Binkley, J.S.; Pople, J.A.; Hehre, W.J. Self-Consistent Molecular Orbital Methods. 21. Small SplitValence Basis Sets for First-Row Elements. J. Am. Chem. Soc. 1980, 102, 939-947.

(34) Tomasi, J.; Mennucci, B.; Cammi, R. Quantum Mechanical Continuum Solvation Models. Chem. Rev. 2005, 105, 2999-3093.

(35) Bauernschmitt, R.; Ahlrichs, R. Treatment of Electronic Excitations within the Adiabatic Approximation of Time Dependent Density Functional Theory. Chem. Phys. Lett. 1996, 256, 454464.

(36) Schaftenaar, G.; Noordik, J.H. Molden: A Pre- and Post-Processing Program for Molecular and Electronic Structures. J. Comput.-Aided Mol. Design 2000, 14, 123-134.

(37) Gabe, Y.; Urano, Y.; Kikuchi, K.; Kojima, H.; Nagano, T. Highly Sensitive Fluorescence Probes for Nitric Oxide Based on Boron Dipyrromethene Chromophorerational Design of Potentially Useful Bioimaging Fluorescence Probe. J. Am. Chem. Soc. 2004, 126, 3357-3367. 
(38) Yogo, T.; Urano, Y.; Ishitsuka, Y.; Maniwa, F.; Nagano, T. Highly Efficient and Photostable Photosensitizer Based on Bodipy Chromophore. J. Am. Chem. Soc. 2005, 127, 12162-12163.

(39) Prieto, J.B.; Arbeloa, F.L.; Martinez, V.M.; Lopez, T.A.; Arbeloa, I.L. Structural and Spectroscopic Characteristics of Pyrromethene 567 Laser Dye. A Theoretical Approach. Phys. Chem. Chem. Phys. 2004, 6, 4247-4253.

(40) Du, P.; Schneider, J.; Luo, G.; Brennessel, W.W.; Eisenberg, R. Visible Light-Driven Hydrogen Production from Aqueous Protons Catalyzed by Molecular Cobaloxime Catalysts. Inorg. Chem. 2009, 48, 4952-4962.

(41) Li, C.; Wang, M.; Pan, J.; Zhang, P.; Zhang, R.; Sun, L. Photochemical Hydrogen Production Catalyzed by Polypyridyl Ruthenium-Cobaloxime Heterobinuclear Complexes with Different Bridges. J. Organomet. Chem. 2009, 694, 2814-2819.

(42) McCormick, T.M.; Han, Z.; Weinberg, D.J.; Brennessel, W.W.; Holland, P.L.; Eisenberg, R. Impact of Ligand Exchange in Hydrogen Production from Cobaloxime-Containing Photocatalytic Systems. Inorg. Chem. 2011, 50, 10660-10666.

(43) Zhang, P.; Wang, M.; Li, C.; Li, X.; Dong, J.; Sun, L. Photochemical H2 Production with NobleMetal-Free Molecular Devices Comprising a Porphyrin Photosensitizer and a Cobaloxime Catalyst. Chem. Comm. 2010, 46, 8806-8808.

(44) Peuntinger, K.; Lazarides, T.; Dafnomili, D.; Charalambidis, G.; Landrou, G.; Kahnt, A.; Sabatini, R.P.; McCamant, D.W.; Gryko, D.T.; Coutsolelos, A.G.et al. Photoinduced Charge Transfer in Porphyrin-Cobaloxime and Corrole-Cobaloxime Hybrids. J. Phys. Chem. C 2012, 117, 1647-1655.

(45) Coe, B.J. Switchable Nonlinear Optical Metallochromophores with Pyridinium Electron Acceptor Groups. Acc. Chem. Res. 2006, 39, 383-393.

(46) Cheng, M.; Yang, X.; Li, J.; Chen, C.; Zhao, J.; Wang, Y.; Sun, L. Dye-Sensitized Solar Cells Based on a Donor-Acceptor System with a Pyridine Cation as an Electron-Withdrawing Anchoring Group. Chemistry Eur. J. 2012, 18, 16196-16202. 
TOC graphic:

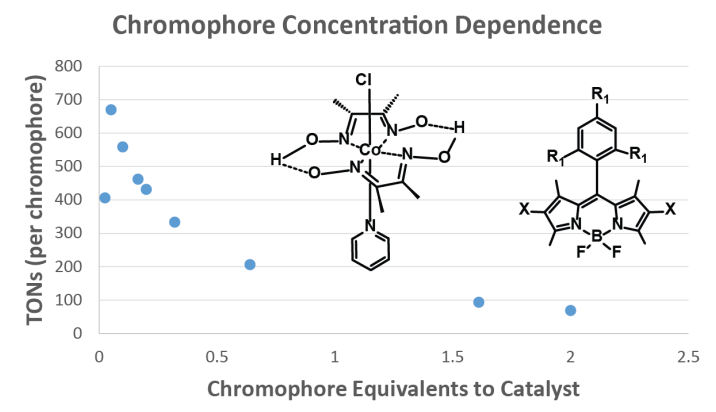

15

16

17

18

19

20

21

22

23

24

25

26

27

28

29

30

31

32

33

34

35

36

37

38

39

40

41

42

43

44

45

46

47

48

49

50

51

52

53

54

55

56

57

58

59

60 

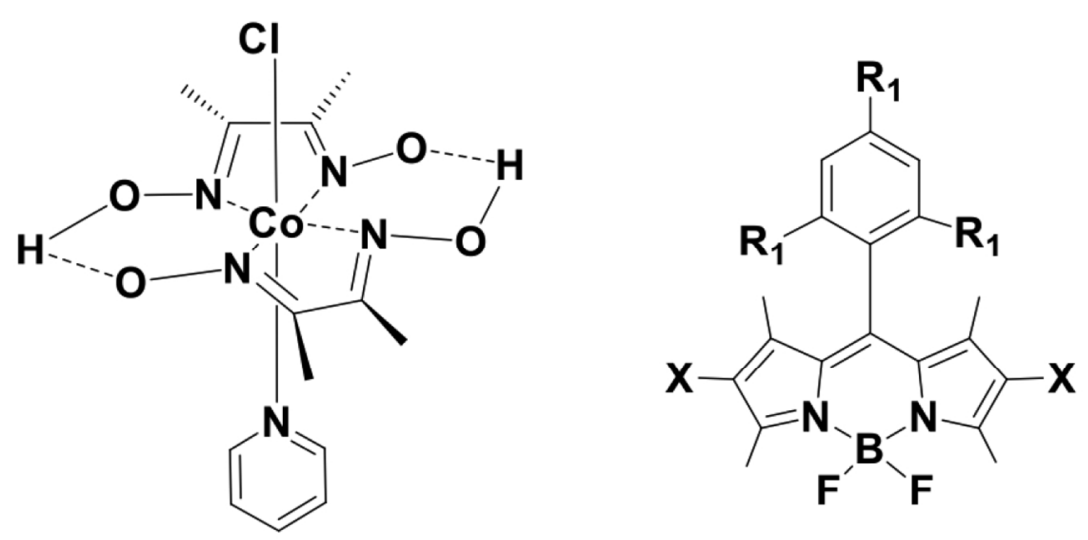

19

20

21

22

2a: $X=H, R_{1}=H \quad$ 3a: $X=H, R_{1}=C_{3}$

1

2b: $X=B r, R_{1}=H \quad$ 3b: $X=B r, R_{1}=C_{3}$

2c: $X=I, R_{1}=H \quad 3 c: X=I, R_{1}=C_{3}$

Figure 1: Structures of the catalyst and chromophores used in this study. $574 \times 317 \mathrm{~mm}(72 \times 72 \mathrm{DPI})$ 


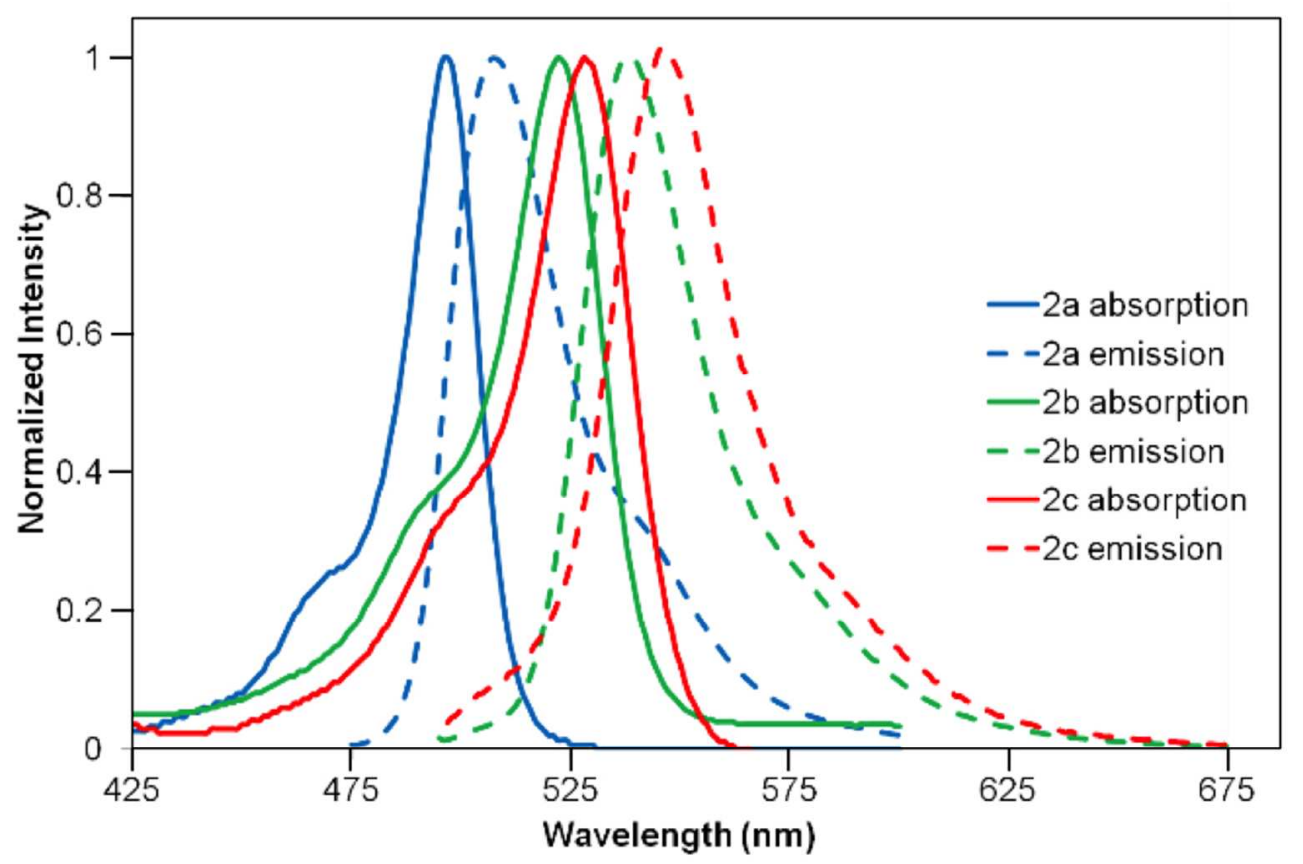

Figure 2: Normalized absorption (solid) and emission (dashed) spectra of series 2 photosensitizers. $375 \times 250 \mathrm{~mm}(72 \times 72 \mathrm{DPI})$ 


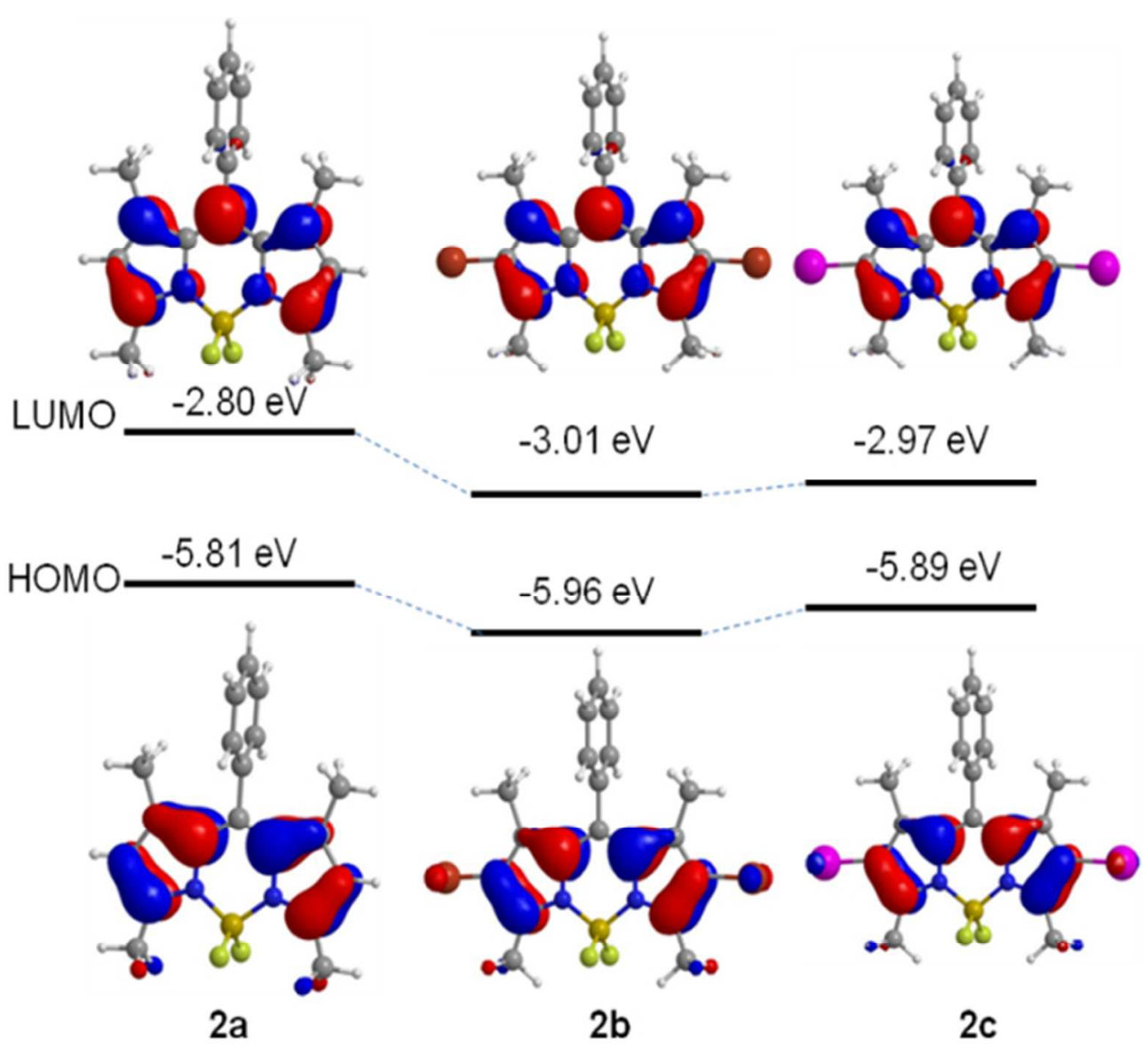

Figure 3: HOMO and LUMO energy levels for 2a-c molecular orbital diagrams. $76 \times 68 \mathrm{~mm}(220 \times 220 \mathrm{DPI})$ 


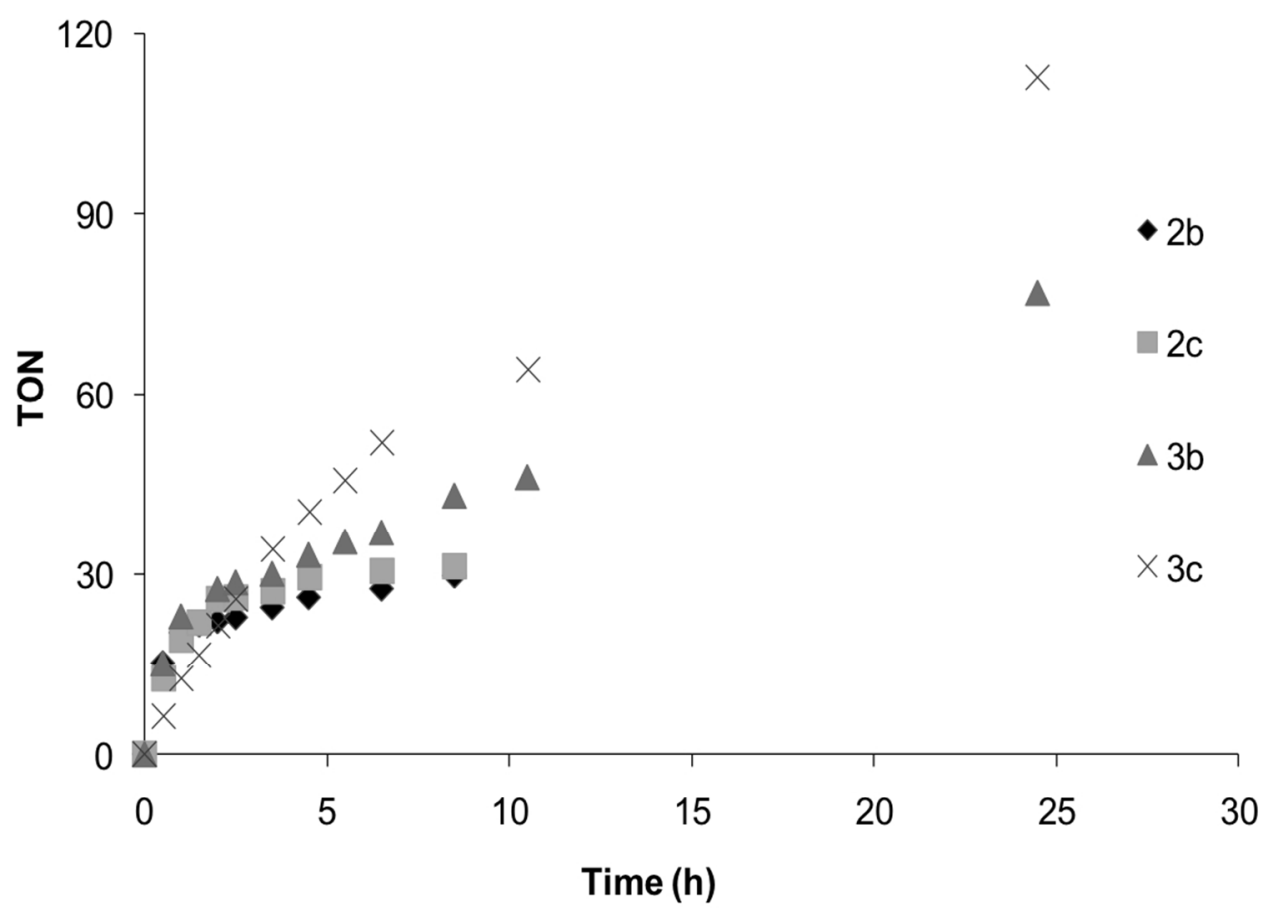

Figure 4: Hydrogen production results for $2 \mathrm{~b}-\mathrm{c}$ and $3 \mathrm{~b}-\mathrm{c}$ with dye concentration of $5.0 \times 10^{\wedge}-5 \mathrm{M}$ and catalyst concentration of $1.0 \times 10^{\wedge}-4 \mathrm{M}$ in $1: 1 \mathrm{MeCN}: 10 \% \mathrm{TEOA}(\mathrm{aq})$ irradiated by $\lambda>410 \mathrm{~nm}$ light. Turnover number (TON) represents moles of hydrogen produced versus moles of photosensitizer. $413 \times 294 \mathrm{~mm}(72 \times 72$ DPI $)$ 


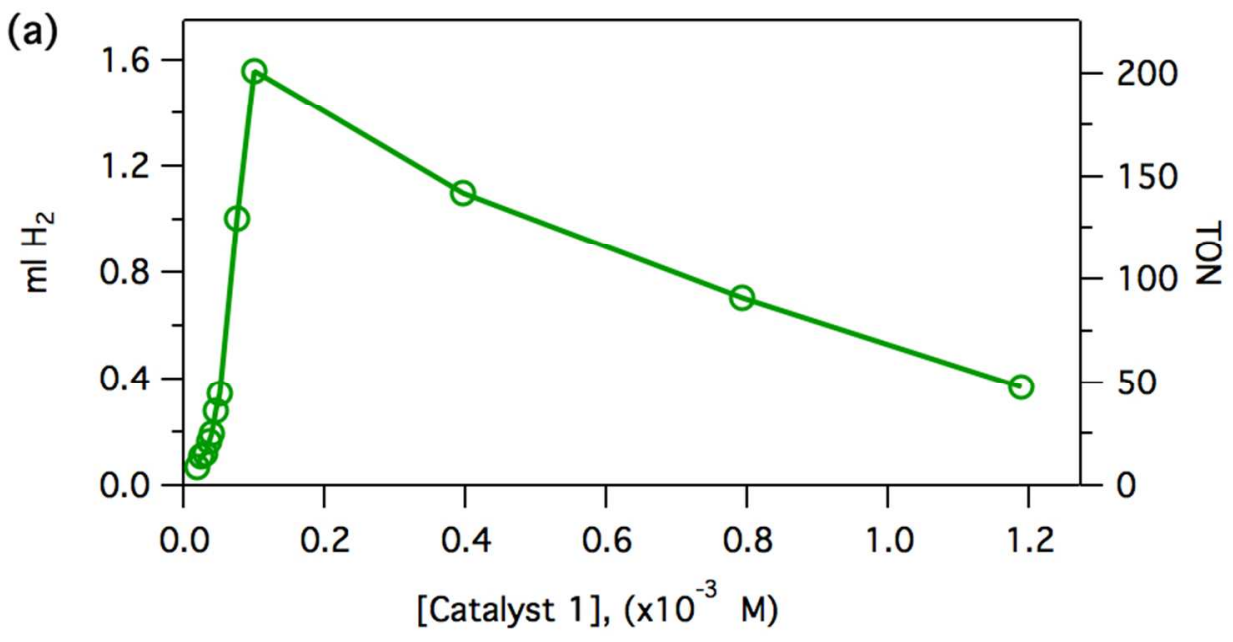

(b)

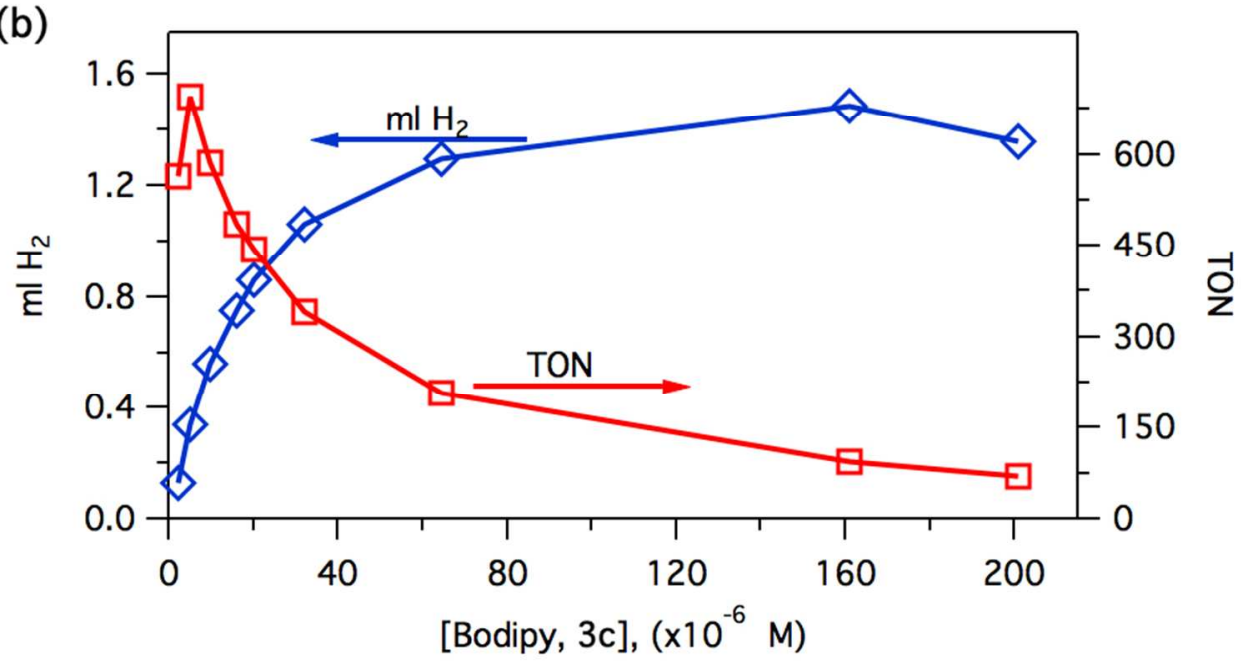

Figure 5: The total amount of evolved hydrogen for (a) varying concentrations of catalyst 1 with a fixed concentration of photosensitizer $3 c\left(8.0 \times 10^{\wedge}-5 \mathrm{M}\right)$, and for $(\mathrm{b})$ varying concentrations of photosensitizer $3 c$ with a fixed concentration of catalyst $1\left(1.0 \times 10^{\wedge}-4 \mathrm{M}\right)$. In each case, TON is calculated relative to photosensitizer concentration. Hence, in (a) the two vertical axes, $\mathrm{ml} \mathrm{H2}$ and TON, are proportional to each other, whereas in (b) the varying concentrations of photosensitizer produce a TON (red, right hand axis) dependence that is very different than the total $\mathrm{ml} \mathrm{H} 2$ produced (blue, left hand axis). $172 \times 184 \mathrm{~mm}(144 \times 144 \mathrm{DPI})$ 


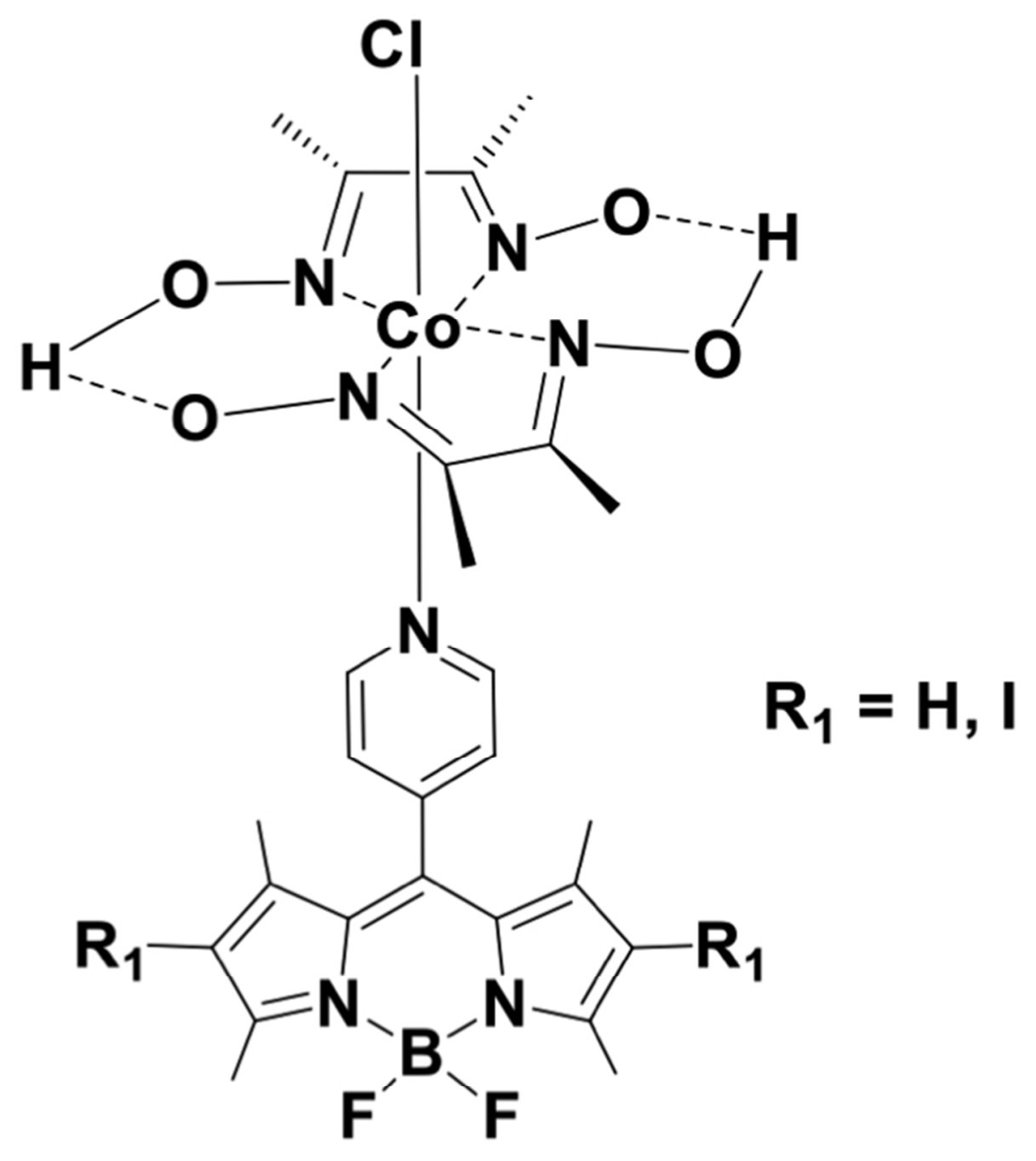

Figure 6: Example of Bodipy - cobaloxime dyad from Reference 16. $252 \times 273 \mathrm{~mm}(72 \times 72 \mathrm{DPI})$ 
TOC Graphic $223 \times 134 \mathrm{~mm}$ (144 x 144 DPI)

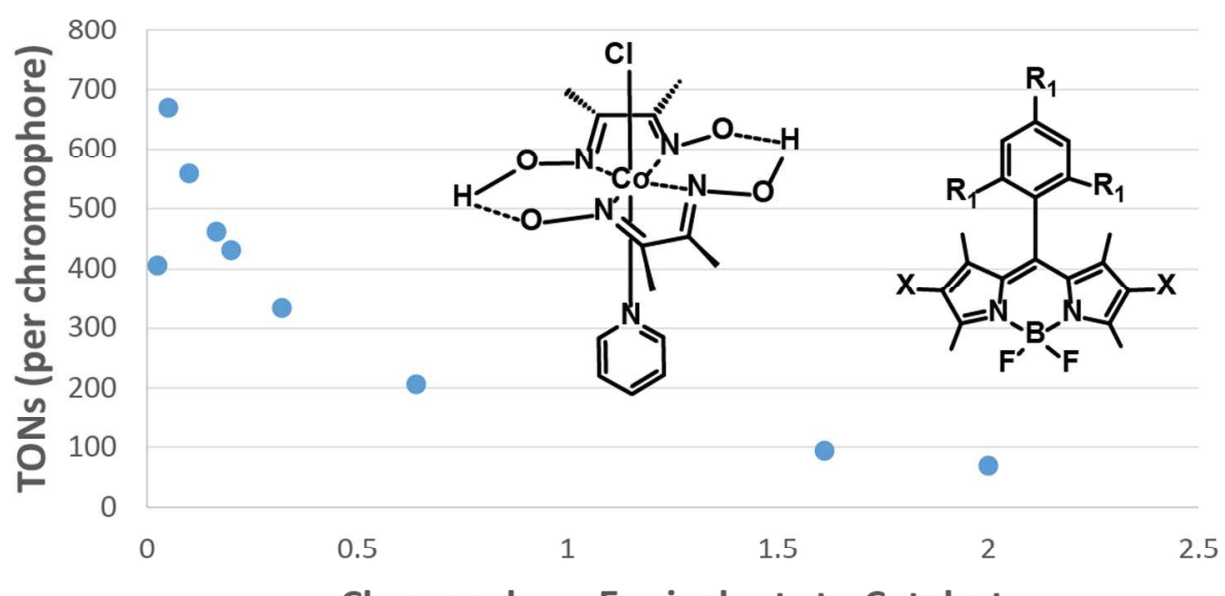

Chromophore Equivalents to Catalyst 